\title{
Quality of care in private sector and NHS facilities for people with dementia: cross sectional survey
}

\author{
Clive Ballard, Jane Fossey, Ramilgan Chithramohan, Robert Howard, Alistair Burns, \\ Peter Thompson, George Tadros, Andrew Fairbairn
}

Editorial

by Marshall

Royal College of

Psychiatrists,

London SW1X 8PG

Clive Ballard

professor of old age

psychiatry

Jane Fossey

consultant clinical

psychologist

Ramilgan

Chithramohan

consultant old age

psychiatrist

Robert Howard

reader in old age

psychiatry

Alistair Burns

professor of old age

psychiatry

Peter Thompson

consultant old age

psychiatrist

George Tadros

specialist registrar in

old age psychiatry

Andrew Fairbairn

consultant old age

psychiatrist

Correspondence to:

Andrew Fairbairn,

Royal College of

Psychiatrists,

London SW1X 8PG

BMJ 2001;323:426-7
Residential and nursing homes provide an essential contribution towards the care of people with dementia. It is a challenge to provide good care within tight budgets and often with a workforce that has little formal training. Most people are cared for within the private sector, although a limited number of NHS beds provide continuing care for people with severe dementia and intractable behaviour problems.

Dementia care mapping ${ }^{1}$ is a direct, standardised assessment with good interrater reliability. ${ }^{2}$ Activities are coded according to category of behaviour, and they are recorded every five minutes. Wellbeing is measured using the dementia care index, which indicates the overall quality of care within a particular environment extrapolated from dementia care mapping evaluations of half of the residents. ${ }^{1}$ We used dementia care mapping to evaluate the quality of care in 10 private sector and seven NHS care facilities.

\section{Participants, methods, and results}

People living in care facilities from specific geographical catchment areas in three regions of the United Kingdom received a standardised assessment from which an operationalised diagnosis of dementia was made. ${ }^{3}$ The facilities in the group included all seven NHS continuing care units and 10 of 12 private sector facilities with more than 35 residents in the designated areas. Dementia care mapping evaluations were completed by researchers from medical, nursing, or psychology backgrounds. All had completed a certified training course and achieved good interrater reliability $(\kappa$ scores $>0.8)$ in a six hour evaluation with a senior mapper. A dementia care index score was calculated, and an overall category was assigned to the quality of care.

A total of 367 people with dementia were identified; of these, dementia care mapping was used to evaluate 218 (59\%) (table).

The dementia care index rated all seven (100\%) NHS facilities (dementia care index rating range - 1.6 to 4.1$)$ and five $(50 \%)$ of the private sector facilities as needing radical improvement (dementia care index rating range $4.1-8.8)$; the remaining five $(50 \%)$ private sector facilities were rated as needing much improvement (dementia care index rating range 12.3-20.4). Over the six hour daytime period of observation, people spent 61 minutes (17\%) asleep and 108 minutes $(30 \%)$ either socially withdrawn or not actively engaged in any form of basic or constructive activity. Only 50 minutes (14\%) were spent talking (or communicating in other ways) with staff or other residents, and less than 12 minutes (3\%) were spent engaged in everyday constructive activities other than watching television (11 minutes (3\%)). The remaining 33\% of the observation period was spent engaged in basic activities such as eating, going to the toilet, etc.

\section{Comment}

Quality of care was rated as needing radical improvement or much improvement in all homes, and no home showed even a fair standard of care. Can our results be regarded as representative? The homes were not selected because of perceived poor standards of care- $17 / 19(89 \%)$ of the large care facilities in the designated area were surveyed, and the characteristics of the residents were consistent with recent reports. Current care provision is inadequate, at least according to dementia care index standards, and urgent action is required. The evaluation methods currently used by joint inspection teams, do not make use of direct observation, so may not be sufficient to fully evaluate the care environment.

Recent reports have highlighted the need for review and improvement of the standards of care in residential and nursing homes. ${ }^{45}$ Our data emphasise the need for urgency in this process. The proposed national standards for care in residential and nursing homes for elderly people describe interaction and daily activity as one of $11 \mathrm{key}$ domains. ${ }^{5}$ These aspects of care require particular attention, and they merit a greater focus within revised standards. Improved strategies for joint working between the NHS, social services, and private care providers will ensure that

Quality of care in 10 private sector and seven NHS care facilities for people with dementia evaluated by dementia care mapping

\begin{tabular}{lccl}
$\begin{array}{l}\text { Facility } \\
\text { Private sector (480 }\end{array}$ & $\begin{array}{c}\text { Meatients, } \mathbf{4 1 3} \text { with dementia) } \boldsymbol{~} \\
\text { score }\end{array}$ & $\begin{array}{c}\text { Dementia care } \\
\text { index rating* }\end{array}$ & Action needed \\
\hline 1 & 1.23 & 12.3 & Much improvement \\
\hline 2 & 1.22 & 18.4 & Much improvement \\
\hline 3 & 1.15 & 17.2 & Much improvement \\
\hline 4 & 1.02 & 20.4 & Much improvement \\
\hline 5 & 0.85 & 12.8 & Much improvement \\
\hline 6 & 0.88 & 8.8 & Radical changes \\
\hline 7 & 0.75 & 7.5 & Radical changes \\
\hline 8 & 0.54 & 8.1 & Radical changes \\
\hline 9 & 0.41 & 4.1 & Radical changes \\
\hline 10 & 0.38 & 5.7 & Radical changes \\
\hline NHS (71 patients, 71 with dementia) $\neq$ & & \\
\hline 1 & 0.81 & 4.1 & Radical changes \\
\hline 2 & 0.65 & 3.3 & Radical changes \\
\hline 3 & 0.60 & 3.0 & Radical changes \\
\hline 4 & 0.31 & 3.1 & Radical changes \\
\hline 5 & 0.25 & 2.4 & Radical changes \\
\hline 6 & 0.23 & 3.5 & Radical changes \\
\hline 7 & -0.32 & -1.6 & Radical changes \\
\hline
\end{tabular}

*Range 0-300; 10=radical changes needed, 10-24=much improvement needed, 25-49=fair, 50-74=good, 75-99=very good, >99=excellent.

tClinical dementia rating scale scores $31 \%$ mild, $32 \%$ moderate, and $37 \%$ severe; median age 83 years; $69 \%$ women; and median neuropsychiatric inventory score 12

$\ddagger C l i n i c a l$ dementia rating scale scores $0 \%$ mild, $0 \%$ moderate, and $100 \%$ severe; median age 79 years; 60\% women; and median neuropsychiatric inventory score 37 
integrated specialist teams can deliver high quality care to these vulnerable patients.

We would like to thank Mental Health Foundation and Research Into Ageing, who funded studies from which some of the data were acquired.

Contributors: All authors helped to formulate the study design, coordinate the collection of data, and write the paper.

$\mathrm{CB}$ undertook the data evaluation and will act as guarantor.

Funding: None.

Competing interests: None declared.

1 Kitwood T, Bredin K. Evaluating dementia care: the DCM method. 7th ed. Bradford: Bradford Dementia Research Group, 1997.
2 Brooker D. Looking at them looking at me. A review of observational studies into the quality of institutional care for elderly people with dementia. J Ment Health 1995;4:145-56.

3 Copeland JR, Kelleher MJ, Kellett JM, Gourlay AJ, Gurland BJ, Fleiss JL et al. A semi structured clinical interview for the assessment of diagnosis and mental state in the elderly. The geriatric mental state schedule: development. Psychol Med 1976;6:439-49.

4 Leaper R, ed. Training and qualifications for work with older people. Report of a national conference with recommendations for action. National Council on Ageing. London: Age Concern, 1998

5 Department of Health. Fit for the Future? National required standards for residential and nursing homes for older people. London: DoH, 1999. www.doh.gov.uk/pub/docs/doh/fitfuture.pdf (accessed 9 May 2001).

(Accepted 6 April 2001)

\section{Prescriptions with potential drug interactions dispensed at Swedish pharmacies in January 1999: cross sectional study}

Juan Merlo, Hans Liedholm, Ulf Lindblad, Agneta Björck-Linné, Jürgen Fält, Gunnar Lindberg, Arne Melander

The growing use of pharmacological agents means that drug interactions are of increasing interest for public health. ${ }^{1}$ Monitoring of potential drug interactions may improve the quality of drug prescribing and dispensing, and it might form a basis for education focused on appropriate prescribing.

\section{Participants, methods, and results}

In a cross sectional study, we analysed all prescriptions $(n=962013)$ involving two or more drugs dispensed to the Swedish population ( $\mathrm{n}=7214509$; age range 15-95) from all Swedish pharmacies $(\mathrm{n}=885)$ in January 1999. The data were taken from the Swedish healthcare database on pharmaceutical agents, which records all prescriptions dispensed at all of the pharmacies in Sweden. Strict registration routines and internal controls support the accuracy of the database.

Data were stratified by age and sex, and odds ratios were calculated using multilevel logistic regression. ${ }^{2}$ Potential drug interactions were classified according to clinical relevance (types A, B, C, and D) and documented evidence (types 1, 2, 3, and 4)-for example, subtype D4 indicates an interaction with greater potential clinical relevance than that classified as subtype A1 (figure). ${ }^{34}$

Of the 962013 prescriptions dispensed by pharmacies, $130765(13.6 \%)$ included at least one potential drug interaction. The number of potential drug interactions increased with the patient's age and with the number of drugs per prescription (data not shown). Clinically relevant potential drug interactions that could be controlled by adjusting the dose (type $\mathrm{C}$ ) were found in 29 991/371402 (8.1\%) men and $44754 / 545857$ (7.6\%) women. Potential interactions that might have serious clinical consequences (type D) were found in 13282 (1.4\%) of the prescriptions (11.4\% (5269/371 402) men and 1.4\% (8013/590 611) women). However, 6936 (52.2\%) of these potential interactions were between ipratropium and $\beta$ adrenergic agonists, which result in an increased risk of acute angle closure glaucoma only when the drugs are used in nebulised form-an uncommon treatment.

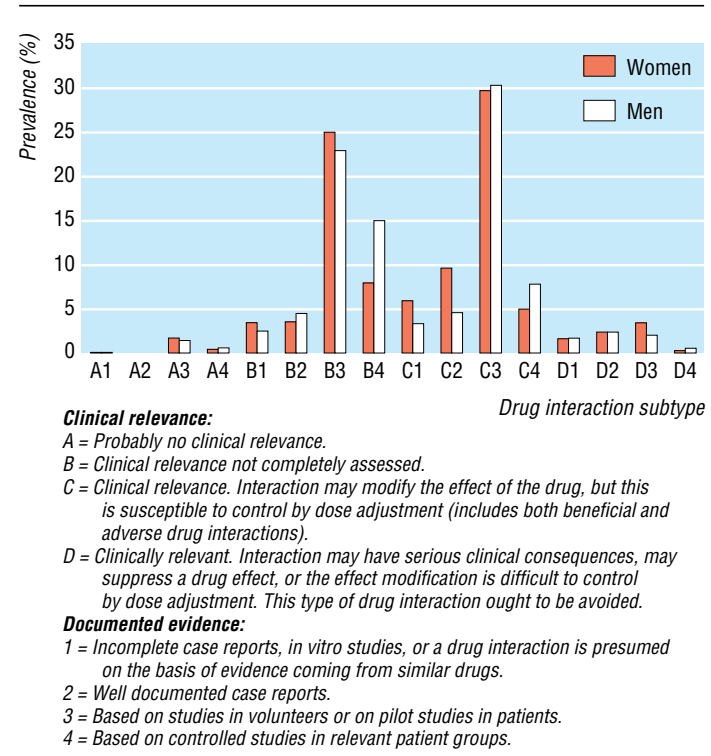

Prevalence of potential drug-drug interaction subtypes ${ }^{34}$ among 962013 prescriptions containing two or more drugs dispensed to patients aged 15-95 from Swedish pharmacies in January 1999.

After adjusting for the number of drugs dispensed, we found that combinations of drugs with potential interactions that may have serious clinical consequences (type D) were less likely to be prescribed to women than men (relative risk $0.88 ; 95 \%$ confidence interval 0.85 to 0.92 ).

Of the potential type D interactions, 2358 were between potassium supplements and potassium sparing diuretics - a combination that may result in severe and even life threatening hyperkalaemia. The combination of warfarin dispensed with a nonsteroidal anti-inflammatory drug (subtype D4), which can increase the risk of gastrointestinal bleeding due to gastric mucosal damage by the non-steroidal antiinflammatory drug and the anticoagulant effect of warfarin, was found on 644 occasions.
Department of
Community
Medicine, Lund
University, Malmö
University Hospital,
S-205 02 Malmö,
Sweden 